\title{
Sorafenib and TRAIL have synergistic effect on hepatocellular carcinoma
}

\author{
KEIICHIRO NOJIRI ${ }^{1}$, KAZUSHI SUGIMOTO $^{1,3}$, KATSUYA SHIRAKI ${ }^{1}$, MASAHIKO TAMEDA $^{1,3}$, \\ YUUJI INAGAKI ${ }^{1}$, SUGURU OGURA ${ }^{1}$, CHIKA KASAI $^{1}$, SATOKO KUSAGAWA ${ }^{1}$, MISAO YONEDA ${ }^{1}$, \\ NORIHIKO YAMAMOTO ${ }^{1}$, YOSHIYUKI TAKEI ${ }^{2}$, TSUTOMU NOBORI ${ }^{3}$ and MASAAKI ITO ${ }^{1}$ \\ ${ }^{1}$ First Department of Internal Medicine, Departments of ${ }^{2}$ Gastroenterology, ${ }^{3}$ Molecular and Laboratory Medicine, \\ Mie University School of Medicine, Tsu, Japan
}

Received June 11, 2012; Accepted August 21, 2012

DOI: $10.3892 /$ ijo.2012.1676

\begin{abstract}
A multi-kinase inhibitor, sorafenib, was recently approved and is currently recommended for the treatment of advanced hepatocellular carcinoma (HCC). However, HCC treatment outcomes are still poor and necessitate improvement. Therefore, we investigated the influence of sorafenib in combination with each of cytotoxic chemotherapy agents, hypoxia or tumor necrosis factor (TNF)-related apoptosis-inducing ligand (TRAIL), on cytotoxicity to determine which is the better adjuvant. Additive cytotoxicity of sorafenib to chemotherapy agents, hypoxia and TRAIL, to HCC cells was assessed using cell viability assay. Intracellular levels of anti-apoptotic proteins were determined using western blot analysis. Activation of Wnt/ $\beta$-catenin signaling was assessed using a luciferase reporter gene assay. Sorafenib significantly and synergistically enhanced the cytotoxicity of TRAIL to HCC cells and 4',6-diamidino2-phenylindole (DAPI) staining showed increased apoptosis among cells treated with sorafenib and TRAIL. This augmentation in cytotoxicity was derived from sorafenib-mediated downregulation of anti-apoptotic proteins. However, sorafenib did not enhance the cytotoxicity of chemotherapy agents (cisplatin, 5-FU or doxorubicin) or hypoxic treatment to HCC. Moreover, hypoxic treatment induced Wnt/ $\beta$-catenin signaling activation. Our data showed that in combination TRAIL and sorafenib had a synergistic cytokilling effect on HCC cells and that this effect derived from sorafenib-mediated downregulation of anti-apoptotic proteins.
\end{abstract}

\section{Introduction}

Hepatocellular carcinoma (HCC) is the most common primary malignancy of the liver in adults. It is the fifth most common

Correspondence to: Dr Kazushi Sugimoto, First Department of Internal Medicine, Department of Molecular and Laboratory Medicine, Mie University School of Medicine, 2-174 Edobashi, Tsu, Mie 514-8507, Japan

E-mail: kazushi@clin.medic.mie-u.ac.jp

Key words: sorafenib, tumor necrosis factor-related apoptosis-inducing ligand, hepatocellular carcinoma solid tumor worldwide and the third leading cause of cancer mortality with more than 1 million deaths annually.

Historically, surgical resection has been performed as a curative therapy; more recently, local radiofrequency ablation (RFA) has been developed. In addition, orthotopic liver transplantation (OLT) has become a therapeutic option for patients with HCC. Currently transarterial chemoembolization (TACE) is the most widely performed treatment for non-resectable HCCs, and results from randomized controlled trials show a clear survival benefit after TACE when compared with conservative management $(1,2)$. Systemic or arterial infusion of chemotherapeutic drugs is also used to treat non-resectable or metastatic HCC.

Several factors make it difficult to treat HCC completely. First, most patients have underlying liver disease (e.g., liver cirrhosis due to chronic hepatitis $\mathrm{C}$ or hepatitis $\mathrm{B}$ virus infection) and impaired liver function; therefore, curative resection or ablation is often impossible. Second, HCC has a high rate of recurrence that is caused by intrahepatic metastasis or multicentric occurrence. Reportedly, the tumor recurrence rate exceeds $70 \%$ at 5 years even after curative resection $(3,4)$. Similarly, tumor recurrence after OLT is the major obstacle in preventing successful liver transplantation in patient with HCC (5). No adjuvant therapy has been proven to be effective to reduce recurrence rates. Third, HCC is resistant to conventional cytotoxic chemotherapeutic agents. For example, tumor response rates for single or multiple agent chemotherapy regimens are reportedly low and lack durable remission; these low rates lead to a 1-year survival between 0 to $30 \%$ (6). Until recently, level 1 evidence that systemic chemotherapy improves median overall survival in patients with $\mathrm{HCC}$ has been lacking.

Recently, an oral multi-kinase inhibitor, sorafenib, has become a key drug for treatment of non-resectable HCC. The results of phase III trials in Europe and Asia showed that sorafenib increased the overall survival rate in patients with advanced HCC $(7,8)$. Sorafenib inhibits the serine/threonine kinase activity of Raf-1 and B-Raf and the receptor tyrosine kinase activity of vascular endothelial growth factor receptors (VEGFRs) 1, 2 and 3 and platelet-derived growth factor receptor- $\beta$ (PDGFR- $\beta$ ) $(9,10)$, the cellular signalings of which are implicated in the molecular pathogenesis of HCC. Despite the encouraging results of sorafenib for patients with advanced 
HCC, treatment outcomes are still poor and necessitate improvement. Several clinical trials have shown that combination therapies of sorafenib and TACE or infusion of a cytotoxic chemotherapeutic agent are effective for HCC (11-16); however, these combinations had only modest survival benefits.

TRAIL selectively induces apoptosis in various transformed cell lines. Although HCC cells express TRAIL receptors, these cells are resistant to TRAIL-induced apoptosis $(17,18)$. However, sorafenib may sensitize HCC cells to TRAIL-induced apoptosis (19-21).

Given these former results, it is still unclear whether hypoxia, TRAIL or cytotoxic chemotherapeutic agents is the better adjuvant to sorafenib in the treatment of HCC; therefore, we investigated their effects in combination with sorafenib on two HCC cell lines.

\section{Material and methods}

Cell lines and reagents. The human HCC cell lines, HepG2 and Huh 7, were purchased from the Riken Bioresource Center Cell Bank (Tsukuba, Japan). Both cell lines were cultured in Dulbecco's modified Eagle's medium (DMEM) (Sigma-Aldrich, St. Louis, MO, USA) supplemented with $1 \%$ penicillin/streptomycin (Gibco-BRL, Grand Island, NY, USA) and $10 \%$ heat-inactivated fetal calf serum (FCS) (Gibco-BRL). Recombinant TRAIL was purchased from R\&D Systems (Minneapolis, MN, USA). Sorafenib was purchased from LC Laboratories (Woburn, MA, USA). Cisplatin (CDDP), fluorouracil (5-FU) and doxorubicin were purchased from Sigma-Aldrich.

\section{Cell proliferation and viability assays}

MTT assay. HCC cells were plated at a density of $1 \times 10^{4}$ cells per well in 96-well microtiter plates (Corning Glass Works, Corning, NY, USA) and each plate was incubated for $5 \mathrm{~h}$ at $37^{\circ} \mathrm{C}$ in $5 \% \mathrm{CO}_{2}$. Next, $50 \mu \mathrm{l}$ of a drug solution was added to each well and the plates were incubated for $48 \mathrm{~h}$. The live-cell count was assayed using a Cell Titer 96 Assay kit (Promega, Madison, WI, USA) according to the manufacturer's instructions. The absorbance of the contents of each well was measured at $570 \mathrm{~nm}$ with a microtiter plate reader (Bio-Rad Laboratories, Hercules, CA, USA).

$x$ CELLigence system. Cell proliferation and viability was also assessed with xCELLigence system (Roche Inc., Basel, Switzerland) according to manufacturer's instruction. Briefly, each well of each 16-well microtiter plate (E-Plate 16) was filled with $100 \mu \mathrm{l}$ of DMEM to equilibrate the well membrane, and each plate was incubated for $30 \mathrm{~min}$ at $37^{\circ} \mathrm{C}$ in $5 \% \mathrm{CO}_{2}$. $\mathrm{HCC}$ cells suspended in $50 \mu \mathrm{l}$ of growth medium were seeded at a density of $1 \times 10^{4}$ cells per well. Cells were cultured for 12 to 48 h, with the Real-Time Cell Analyzer (RTCA) single plate (SP). Instrument placed in a standard incubator at $37^{\circ} \mathrm{C}$ in $5 \% \mathrm{CO}_{2}$, followed by addition of $50 \mu \mathrm{l}$ of drug solution. Then, cell proliferation was monitored by recording Cell Index (CI) values at $15 \mathrm{~min}$ intervals for $48 \mathrm{~h}$.

Detection of apoptosis-related proteins on immunoblots. Expression of survivin, FLIP, XIAP and Bcl-xL in HCC cell lines were analyzed using immunoblots. Briefly, cells were harvested after stimulation with sorafenib $(0,2,5,10 \mu \mathrm{M})$ for
24 h. Cells were lysed on ice in lysis buffer $(50 \mathrm{mM} / 1 \mathrm{Tris}-\mathrm{HCl}$ $\mathrm{pH} 8.0,150 \mathrm{mM} / 1 \mathrm{NaCl}, 5 \mathrm{mM} / 1$ ethylenediaminetetraacetic acid, $1 \%$ NP-40, $1 \mathrm{mM}$ phenylmethylsulfonyl fluoride). Each mixture was subjected to centrifugation, each supernatant was collected and the protein content of each sample was measured using the Bio-Rad protein assay kit (Bio-Rad Laboratories). Aliquots from each sample containing equal amounts of protein were subjected to $14 \%$ sodium dodecyl sulfatepolyacrylamide gel electrophoresis (SDS-PAGE) and the separated proteins were transferred onto nitrocellulose membranes (Toyo Roshi, Tokyo, Japan) using the Bio-Rad electrotransfer system (Bio-Rad Laboratories). Blots were incubated in 5\% milk with Tris- $\mathrm{HCl} \mathrm{pH} 7.5$ and $0.1 \%$ Tween-20 for $2 \mathrm{~h}$ at room temperature to block non-specific antibody binding; blots were then incubated overnight at $4{ }^{\circ} \mathrm{C}$ with mouse anti-survivin antibody (Santa Cruz Biotechnology, Santa Cruz, CA, USA), mouse anti-FLICE inhibitory protein (FLIP) monoclonal antibody (Medical \& Biological Laboratories Co., Nagoya, Japan), rabbit anti-B cell lymphoma-extra large (Bcl-xL) polyclonal antibody (Transduction, Lexington, KY, USA), or mouse anti-X-linked inhibitor of apoptosis protein (XIAP) monoclonal antibody (Transduction), diluted 1:1,000 with $5 \%$ skim milk in Tris- $\mathrm{HCl}(\mathrm{pH} 7.5)$ and $0.1 \%$ Tween-20. The immunoblots were then washed and incubated with horseradish peroxidase conjugated anti-mouse monoclonal IgG or horseradish peroxidase-conjugated anti-rabbit IgG (diluted 1:2,000 with 5\% milk in Tris- $\mathrm{HCl} \mathrm{pH} 7.5$ ). Finally, after 3 washes, signals were detected using an ECL kit (Amersham Pharmacia Biotech, Buckinghamshire, UK).

Detection of apoptosis. HepG2 cells $\left(1 \times 10^{4}\right.$ cell/dish) were cultured in 35-mm dishes for $24 \mathrm{~h}$, then $100 \mathrm{ng} / \mathrm{ml}$ of recombinant human TRAIL, $2 \mu \mathrm{M}$ of sorafenib or both were added to each culture. After incubation for $24 \mathrm{~h}$, cell nuclei were stained with DAPI (Sigma-Aldrich) and examined with a fluorescence microscope (Zeiss, Gottingen, Germany).

Wnt reporter gene assay. Human HCC cells, HepG2 or Huh7, were incubated in 96 -well plates at a density of $1.5 \times 10^{4}$ cells/well for $24 \mathrm{~h}$ at $37^{\circ} \mathrm{C}$. The cells were transfected with Cignal TCF/LEF Reporter luc vector (Qiagen, Tokyo, Japan) using the FuGENE HD Transfection Reagent (Roche Applied Science, Mannheim, Germany) and incubated for $24 \mathrm{~h}$ at $37^{\circ} \mathrm{C}$. Cells were stimulated with $2 \mu \mathrm{M}$ of sorafenib for 24 or $48 \mathrm{~h}$. Luciferase activity was determined from cell extracts using the Dual-Glo luciferase assay system (Promega) and a 2030 ARVO X luminometer (Perkin-Elmer, Waltham, MA, USA) according to the manufacturer's instruction.

Inducing hypoxia. HCC cells were plated at a density of $1 \times 10^{4}$ cells per well in 96-well microtiter plates, and each plate was incubated for $24 \mathrm{~h}$ at $37^{\circ} \mathrm{C}$ in $5 \% \mathrm{CO}_{2}$. The media in these plates were replaced with glucose-free and FBS-free media with or without $2 \mu \mathrm{M}$ sorafenib; the plates were then put in a Hypoxia chamber (Veritas Co., Tokyo, Japan), and gas mixture of $5 \% \mathrm{CO}_{2}$ and $95 \% \mathrm{~N}_{2}$ was flushed through the chamber at the flow rate of 2 liters per min for $10 \mathrm{~min}$. The chamber was then incubated for $48 \mathrm{~h}$ at $37^{\circ} \mathrm{C}$ in $5 \% \mathrm{CO}_{2}$. The live-cell count was determined using a Cell Titer 96 Assay kit (Promega) as previously described. In addition, the TCF/LEF reporter gene assay describe above was also performed using these hypoxic cells. 
(a)

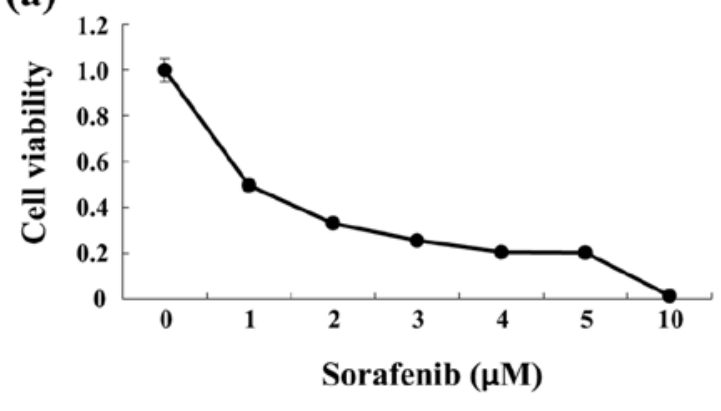

(b)

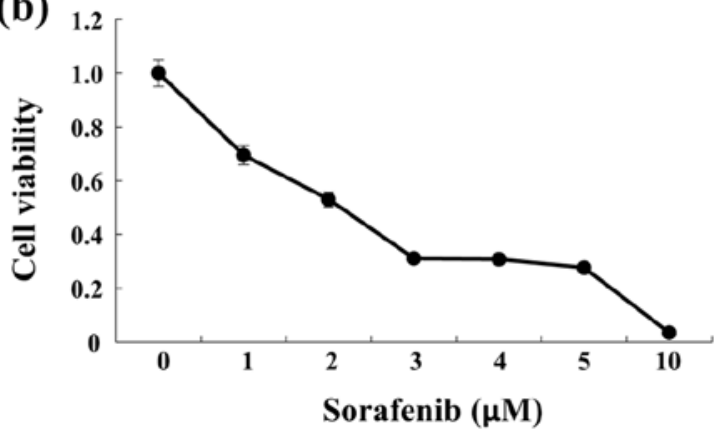

Figure 1. Effect of sorafenib on HCC cell lines. (A) HepG2, (B) Huh7. HCC cells were incubated with the indicated concentrations of sorafenib for 48 h. Cell viability was assessed using the MTT assay. Data are expressed as the mean \pm SD of six independent experiments.

\section{HepG2}

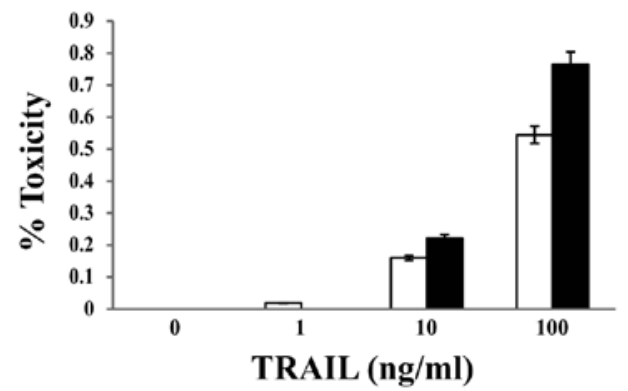

Huh 7

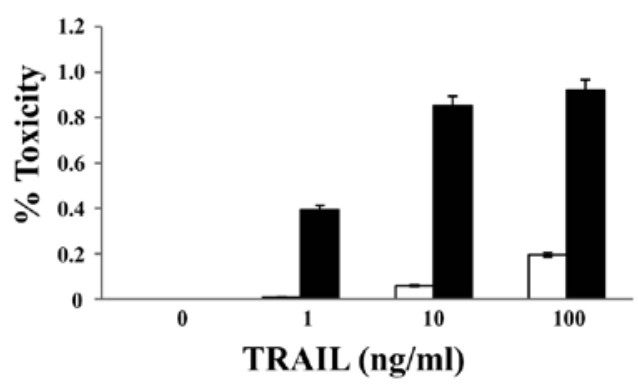

Figure 2. Effects of the combination of sorafenib and TRAIL on HCC cells. HCC cells were incubated with the indicated concentrations of sorafenib and TRAIL for 24 or $48 \mathrm{~h}$. Cell viability was assessed using the MTT assay and the xCELLigence system. Percent lethality in HCC cells incubated with $0,1,10$ and $100 \mathrm{ng} / \mathrm{ml}$ of TRAIL alone ( $\square$ ), with $0,1,10,100 \mathrm{ng} / \mathrm{ml}$ of TRAIL and $2 \mu \mathrm{M}$ sorafenib ( $\mathbf{\square})$ were determined relative to control cells. Data are expressed as the mean \pm SD of six independent experiments.

\section{Results}

Sorafenib reduced viability of HCC cells. To investigate changes in cell viability in response to sorafenib, HCC cells (HepG2 or Huh7) were incubated with various concentrations of sorafenib for $48 \mathrm{~h}$. Sorafenib decreased cell viability of HepG2 and Huh7 cells in a concentration-dependent manner (Fig. 1).

Sorafenib augmented TRAIL-induced apoptosis in two HCC cell lines. The effects of TRAIL in combination with sorafenib treatment on HCC cells were examined. We incubated human HCC cells, with or without $2 \mu \mathrm{M}$ of sorafenib, with one of four concentrations $(0,1,10$ or $100 \mathrm{ng} / \mathrm{ml})$ of recombinant human TRAIL; each concentration is clinically relevant in patients. Cell viability was assessed after 48 h. Surprisingly, the percentage of dead cells (HepG2 and Huh7) was higher for cells treated with $2 \mu \mathrm{M}$ sorafenib and $100 \mathrm{ng} / \mathrm{ml}$ TRAIL than for those treated with only $100 \mathrm{ng} / \mathrm{ml}$ TRAIL (Fig. 2). In fact, the percent lethality for Huh7 cells was approximately $19 \%$ when treated with only $100 \mathrm{ng} / \mathrm{ml}$ TRAIL, but it increased to approximately $92 \%$ when cells were treated with $2 \mu \mathrm{M}$ sorafenib and $100 \mathrm{ng} / \mathrm{ml}$ TRAIL (Fig. 2). The cytotoxicity, as assessed using the xCELLingence system, was similar to that determined by MTT assay (data not shown). These results indicated that the combination of TRAIL and sorafenib has synergistic effects on cytotoxicity for HCC cells.

To assess whether sorafenib could induce apoptosis in HCC cells, we stained HepG2 cells with DAPI $24 \mathrm{~h}$ after treatment with $10 \mathrm{ng} / \mathrm{ml}$ recombinant human TRAIL and $2 \mu \mathrm{M}$ sorafenib. HepG2 cells treated with TRAIL and sorafenib showed features typical of apoptosis (Fig. 3). Based on these findings, we concluded that the reduced viability of these cells was due to augmented apoptosis.

Sorafenib suppressed expression of apoptosis-related proteins. Next, we used immunoblots to investigate the effects of sorafenib on intracellular levels of survivin, FLIP, XIAP and Bcl-xL because these proteins play a major role in controlling apoptotic pathways (22-25). In both HepG2 and Huh7, levels of survivin, XIAP and Bcl-xL were markedly reduced in response to sorafenib treatment in a concentration-dependent manner (Fig. 4).

Anticancer drugs did not have synergistic effects with sorafenib on viability of HCC cells. We next investigated the effects of sorafenib in combination with chemotherapy (CDDP, 5-FU or doxorubicin). We cultured human HCC cells with recombinant human $\operatorname{CDDP}(0,10,100,500,1,000 \mu \mathrm{g} / \mathrm{ml}), 5-\mathrm{FU}(0,1,10,100$, 

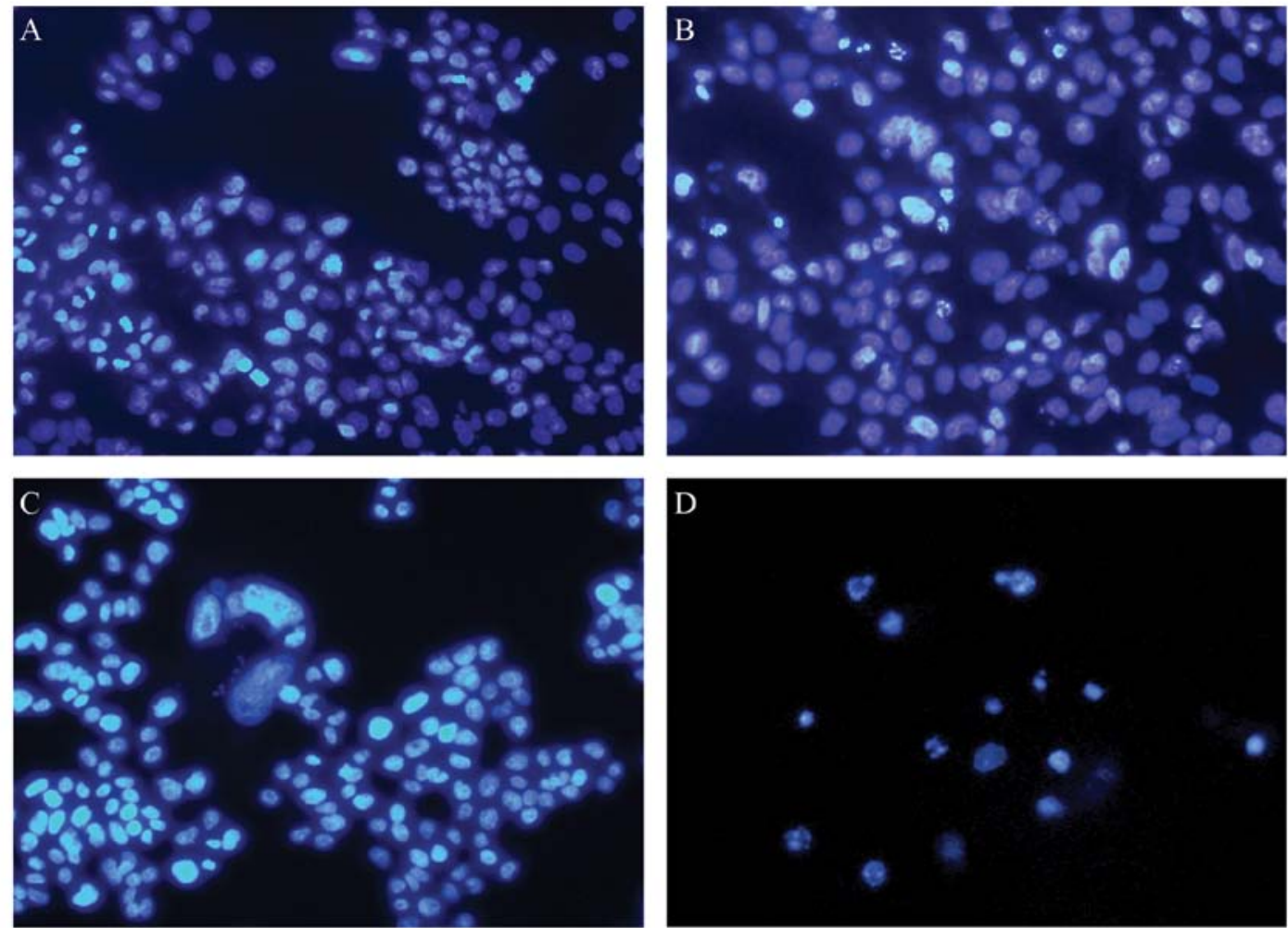

Figure 3. HepG2 cells were incubated for $24 \mathrm{~h}$ with TRAIL $(100 \mathrm{ng} / \mathrm{ml})$ in the absence or presence of a subtoxic level of sorafenib $(2 \mu \mathrm{M})$ and stained with DAPI; (A) control HepG2 cells, (B) TRAIL-treated HepG2 cells, (C) sorafenib-treated HepG2 cells and (D) TRAIL and sorafenib-treated HepG2 cells. (D) showed cells with typical apoptotic features, including nuclear condensation and nuclear fragmentation.

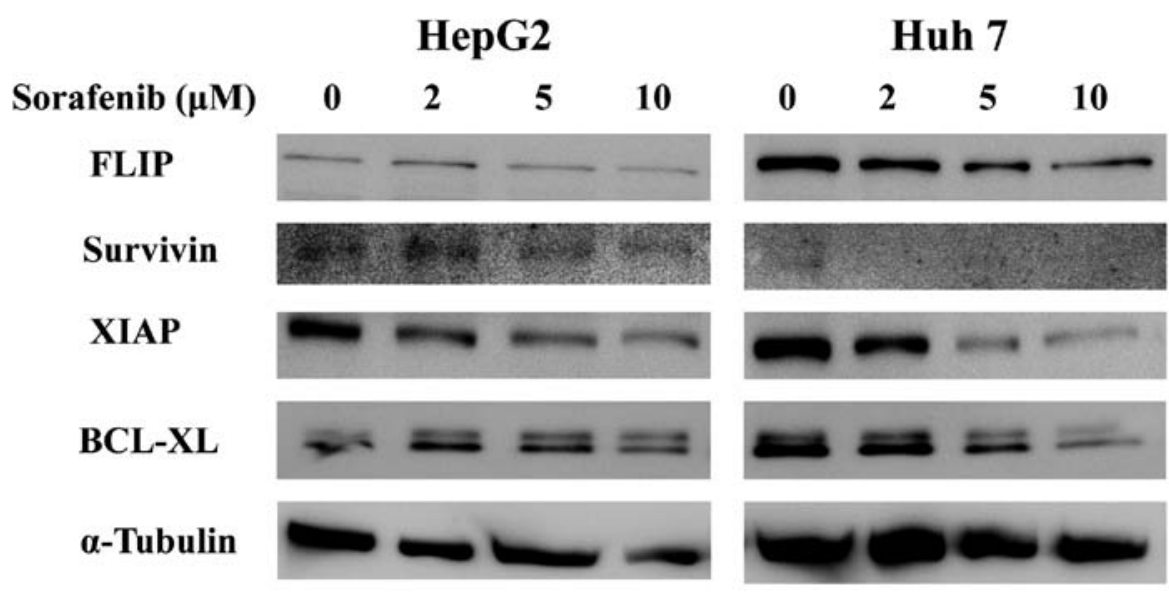

Figure 4. Intracellular expression levels of apoptosis-related proteins in two human HCC cell lines (HepG2 and Huh7) as assessed by western blot analysis.

$500 \mu \mathrm{g} / \mathrm{ml})$, or doxorubicin $(0,0.01,0.1,1,10 \mathrm{mg} / \mathrm{ml})$, which are all clinically relevant doses in patients, in the presence or absence of $2 \mu \mathrm{M}$ sorafenib and cell viability was examined after $48 \mathrm{~h}$. At the highest respective doses, each anticancer agent increased the percentage of dead cells (HepG2 and Huh7), but sorafenib had only a slight cytotoxic effect on the cells. In fact, the percent lethality of $100 \mu \mathrm{g} / \mathrm{ml} \mathrm{CDDP}$ alone versus $100 \mu \mathrm{g} / \mathrm{ml} \mathrm{CDDP}$ and sorafenib were approximately 25 versus $45 \%$, respectively, in HepG2 cells and approximately 13 versus $36 \%$, respectively, in Huh7 cells (Fig. 5). Similar results were obtained with using 5-FU or doxorubicin (data not shown).

Apoptotic activity in of sorafenib is not enhanced in hypoxic HCC cells. Next, we examined the cytotoxic effects of the combination of hypoxia and sorafenib on HCC cells. Both HepG2 and Huh7 cells were divided into four groups; (1) control (sorafenib-, hypoxia-), (2) sorafenib only (2 $\mu \mathrm{M}$ sorafenib+, hypoxia-), (3) hypoxia only (sorafenib-, hypoxia+), (4) sorafenib 
HepG2

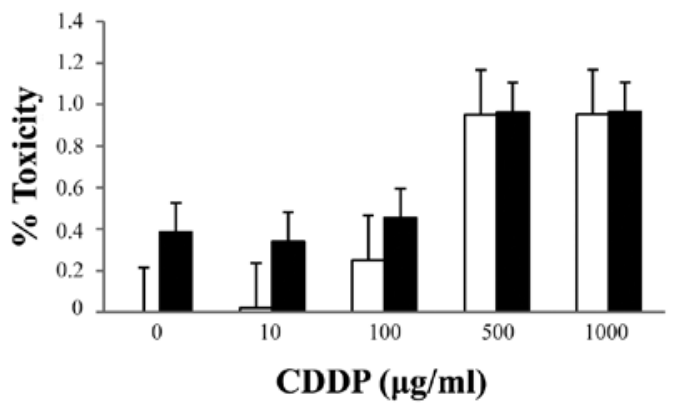

\section{Huh 7}

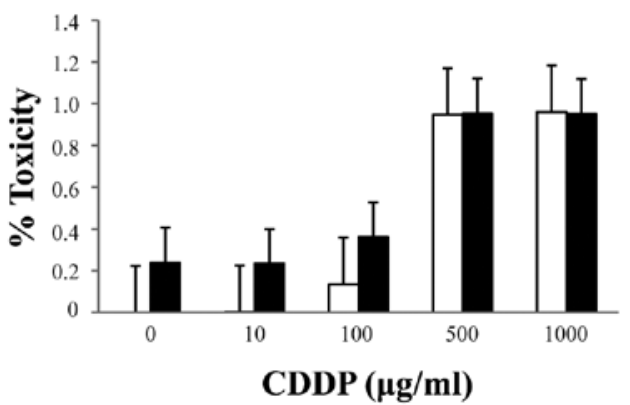

Figure 5. Effect of the combination of sorafenib and CDDP on HCC cells. HCC cells were incubated with various concentrations of CDDP with/without sorafenib for $48 \mathrm{~h}$. Cell viability was assessed using the MTT assay. Percent lethality in HCC cells incubated with 0, 10, 100, 500, or 1,000 $\mu \mathrm{g} / \mathrm{ml}$ CDDP alone ( $\square$ ), or with $0,10,100,500$ or $1,000 \mu \mathrm{g} / \mathrm{ml} \mathrm{CDDP}$ and $2 \mu \mathrm{M}$ sorafenib ( $\mathbf{\square})$ was determined relative to control cells. Data are expressed as the mean \pm SD of six independent experiments.
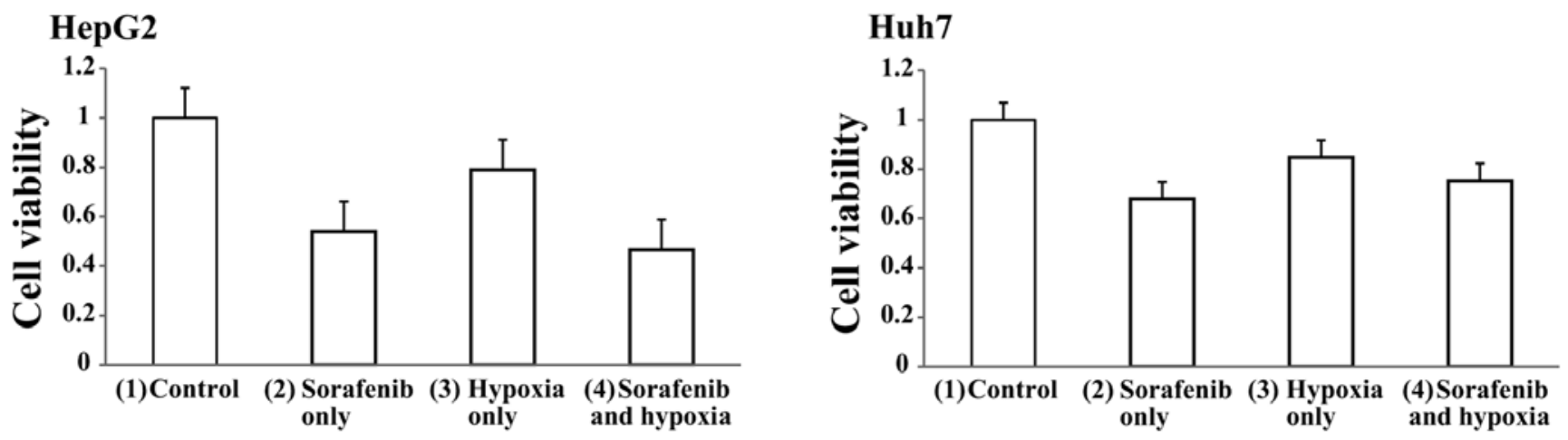

Figure 6. Effect of the combination of sorafenib and hypoxia on HCC cell lines. Both HepG2 and Huh7 cells were divided into four groups; (1) control (sorafenib-, hypoxia-), (2) sorafenib only ( $2 \mu \mathrm{M}$ sorafenib+, hypoxia-), (3) hypoxia only (sorafenib-, hypoxia+), (4) sorafenib and hypoxia (2 $\mu \mathrm{M}$ sorafenib+, hypoxia+). Cell viabilities were assessed using the MTT assay and determined relative to control cells. Data are expressed as the mean \pm SD of six independent experiments.

and hypoxia (2 $\mu \mathrm{M}$ sorafenib+, hypoxia+) and cell viabilities were determined after $48 \mathrm{~h}$ of treatment using the MTT assay. Cell viabilities in HepG2 cells were approximately (2) 55, (3) 80 and (4) $50 \%$ of control cells (Fig. 6A). Similarly, cell viabilities in Huh7 cells were (2) 70, (3) 85 and (4) $80 \%$ of control cells (Fig. 6B). These results indicated that hypoxic treatment did not enhance the effect of sorafenib.

Wnt/ $\beta$-catenin signal are activated by hypoxia in HCC cell lines. Next, to examine whether sorafenib and hypoxia affected the Wnt/ $\beta$-catenin pathway, HCC cells were plated at a density of $1.5 \times 10^{4}$ cells per well in 96-well microtiter plates and incubated for $5 \mathrm{~h}$ at $37^{\circ} \mathrm{C}$. The cells were transfected with the TCF/LEF Reporter using the FuGENE HD Transfection Reagent. After $24 \mathrm{~h}$, the cells were stimulated with $2 \mu \mathrm{M}$ of sorafenib or with nothing and subjected to a normal oxygen concentration or hypoxia for 12 or $24 \mathrm{~h}$. Wnt/ $\beta$-catenin activities were assessed using a luciferase assay as previously described. Both HepG2 and Huh7 cells were divided into four groups; (1) control (sorafenib-, hypoxia-), (2) hypoxia only (sorafenib-, hypoxia+), (3) sorafenib only (2 $\mu \mathrm{M}$ sorafenib+, hypoxia-), (4) sorafenib and hypoxia ( $2 \mu \mathrm{M}$ sorafenib+, hypoxia+). The signal activity ratio of cells in each group relative to control cells after $12 \mathrm{~h}$ were (2) 1.6, (3) 0.7,
(4) 1.4 for HepG2 cells, and (2) 5.0, (3) 1.5, (4) 5.0 for Huh7 cells (Fig. 7A). Similarly, the signal activity ratio of cells in each group after $24 \mathrm{~h}$ was (2) 4.0, (3) 1.3, (4) 2.4 for HepG2 cells and (2) 1.4, (3) 1.4 , (4) 1.9 for Huh7 cells (Fig. 7B). These results indicated that $\mathrm{Wnt} / \beta$-catenin signaling was activated significantly by hypoxia in HCC cells in the presence or absence of sorafenib and that sorafenib alone did not affect Wnt/ $\beta$-catenin signaling.

\section{Discussion}

We examined the effects of sorafenib on TRAIL signaling, on cytotoxic chemotherapeutic agents, and on hypoxia to determine which adjuvant could potentiate a sorafenib-based treatment for HCC. The results demonstrated that TRAIL and sorafenib was the best combination among the treatments examined in this study.

In a phase III trial performed in Europe (SHARP study), sorafenib prolonged the median overall survival of patients with HCC by three months (10.7 months in the sorafenib group and 7.9 months in the placebo group) (7). The sorafenib group also showed prolonged median overall survival compared to the placebo group in a trial in the Asia-Pacific region (6.5 months vs. 4.2 months) (8). Additionally, Kim et al reported that sorafenib 
(A) HepG2

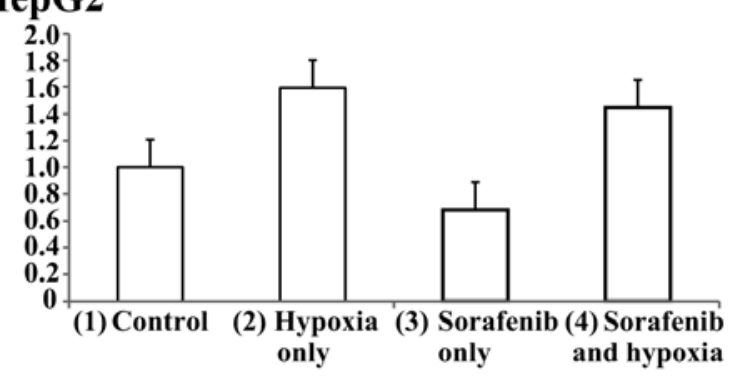

Huh 7

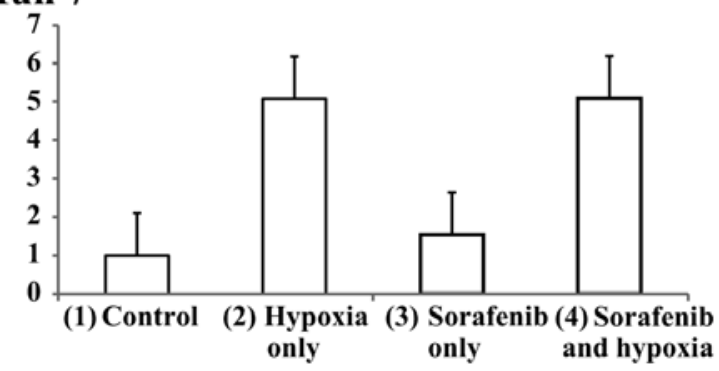

(B) HepG2

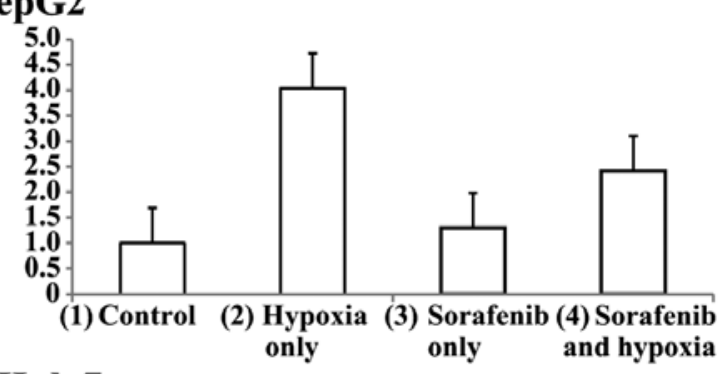

Huh 7

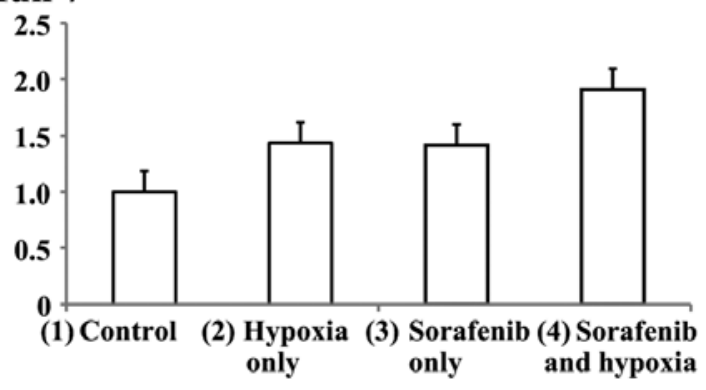

Figure 7. Sorafenib-induced Wnt/ $\beta$-catenin activation in hypoxia environment in HCC cell lines. (A) 12 , (B) 24 h. Both HepG2 and Huh7 cells were divided into four groups; (1) control (sorafenib-, hypoxia-), (2) hypoxia only (sorafenib-, hypoxia+), (3) sorafenib only ( $2 \mu \mathrm{M}$ sorafenib+, hypoxia-), (4) sorafenib and hypoxia (2 $\mu \mathrm{M}$ sorafenib+, hypoxia+). These HCC cells were transfected with the Cignal TCF/LEF Reporter luc vector. Wnt/ $\beta$-catenin activation was analyzed using a Dual-Glo luciferase assay system. The results are presented as the fold induction of the luciferase activity detected in each cell incubated with sorafenib with or without hypoxia for (A) 12 or (B) 24 h compared with control cells. Data are expressed as the mean \pm SD of six independent experiments.

resulted in superior survival in patients with HCC with extrahepatic spread and massive/infiltrative tumors compared to other therapies such as TACE, systemic cytotoxic chemotherapy or radiotherapy (26). The most important characteristic of sorafenib is that it has many points of action. However, despite the advantage over other drugs, sorafenib still does not control the progression of HCC completely, and it does not change prognosis drastically. One reason for the limited efficacy of sorafenib is that HCCs are complex and heterogeneous tumors each with several genomic alternations. Therefore, many key signal transduction pathways are implicated in the pathogenesis of HCC $(27,28)$. Sorafenib does not seem to be able to block all of these signaling pathways, and it is possible that when one pathway is blocked by sorafenib, another pathway is activated to compensate for the loss. Therefore, we believe adjuvant treatment to sorafenib is necessary to improve the outcomes of treatments for HCC.

Here, we found that sorafenib significantly enhanced the cytotoxic effects of TRAIL signaling on HCC cells. Moreover, DAPI staining showed nuclear fragmentation, indicating increased apoptosis. However, similar effects were not observed with Fas ligation (data not shown). TRAIL triggers apoptosis by binding to DR4 or DR5 receptors, and the death domains (DD) of these receptors recruits Fas associated DD-containing protein (FADD), which in turn binds pro-caspase 8. Pro-caspase 8 is then activated by autoproteolytic cleavage, and this activation results in the initiation of apoptotic signaling. TRAIL-based therapies are currently undergoing phase I/II clinical evaluation in cancer patients $(29,30)$. However, many types of cancer cells including HCC are resistant to TRAIL-signaling. Inhibitor of apoptosis (IAPs) are overexpressed on HCC cells and confer tumor cell survival and proliferation mainly by inhibiting the caspase cascade (22-24). Here, we also found that sorafenib downregulated several IAPs (FLIP, Survivin, and XIAP) and Bcl-xL (Fig. 4). Overexpression of these anti-apoptotic proteins is one of the main factors that neutralizes TRAIL-related signaling and causes HCC cells to be resistant to TRAIL. Our results indicated that sorafenib sensitized HCC cells to TRAIL signaling by downregulating these anti-apoptotic proteins. Reportedly, sorafenib inhibits phosphorylation of STAT 3, which regulates expression of numerous apoptosis-related proteins including $\mathrm{Bcl}-\mathrm{xL}, \mathrm{Mcl}-1$ and survivin in pancreas cancer cells and HCC cells $(21,31)$; moreover, Llobet et al have also reported that sorafenib reduces both Mcl-1 and FLIP levels in endometrial cancer cells (32). Our results are consistent with these previous findings; however, all data, including ours, were obtained using cultured cancer cells, and we think further evaluation using in vivo experiments is needed.

We also examined the effect of sorafenib in combination with hypoxia and each of three cytotoxic chemotherapeutic agents (CDDP, 5-FU, or doxorubicin), all of which are routinely used in systemic chemotherapy or TACE for treatment of HCC. Several clinical studies have previously suggested that sorafenib is effective in combination with 5-FU or doxorubicin in the treatment of advanced HCC $(12,13,16)$. However, the effect of these chemotherapeutic drugs in combination with sorafenib cannot be evaluated because the sorafenib-alone groups were not used as the controls in these studies. Our result showed that sorafenib did not add to the effects of any of the chemotherapeutic drugs examined. Though the reasons for this ineffectiveness were not examined in our study, Heim et al showed that sorafenib significantly reduced uptake of platinum compounds by colorectal cancer cell lines (33) and it may be that a similar phenomenon occurred in HCC cells as well. 
In addition, a phase III clinical study comparing TACE plus sorafenib versus TACE plus placebo in patients with HCC is ongoing (11). However, our data demonstrated that hypoxia did not enhance the cytotoxic effect of sorafenib, that sorafenib did not increase the effect of hypoxia on HCC cells and that hypoxic treatment activated $\mathrm{Wnt} / \beta$-catenin signaling in $\mathrm{HCC}$ cells. In the canonical Wnt signaling pathway, $\beta$-catenin plays an important role in cell survival, proliferation and differentiation (34). In the absence of Wnt ligand, $\beta$-catenin is phosphorylated by a cytosolic multiprotein complex that includes axin, adenomatous polyposis coli (APC) and glycogen synthase kinase 3 (GSK-3); then $\beta$-catenin is degraded by the ubiquitin/proteasome system. When Wnt binds the Frizzled trans-membrane receptors, Disheveled (Dsh) inhibits GSK-3 and stabilizes $\beta$-catenin. Accumulated $\beta$-catenin then binds to $\mathrm{T}$ cell-specific transcription factor/lymphoid enhancer-binding factor 1 (TCF/LEF) to transactivate proliferation-related genes. Several studies have indicated that Wnt signaling is modulated by hypoxia. Reportedly, hypoxia-inducible factor- $1 \alpha$ (HIF- $\alpha$ ) suppresses Wnt signaling by directly binding $\beta$-catenin and causing the $\beta$-catenin/TCF/LEF complex to dissociate (35) or by binding arrest defective 1 (ARD1) and inhibiting acetylation of $\beta$-catenin (36). However, other studies have shown that HIF- $\alpha$ enhances $\beta$-catenin activation and expression of TCF/LEF (37) and that, under hypoxic conditions, Wnt signaling promotes hepatocyte survival by involving $\beta$-catenin as a transcriptional coactivator of HIF- $\alpha$ (38). In light of our finding that hypoxia induced activation of $\beta$-catenin-TCF/LEF signaling in HCC cells, it may be that this activation of $\beta$-catenin is, in part, responsible for the reduced efficacy of TACE to HCC.

In conclusion, our data demonstrated that the TRAIL-sorafenib combination has a synergistic cytokilling effect on HCC cells and that this effect derives from the downregulation of anti-apoptotic proteins by sorafenib. We believe that among currently available procedures, TRAIL is the most promising adjuvant to sorafenib for the treatment of HCC; however, we acknowledge that clinical data are still lacking. In this regard, further investigation with clinical trial is necessary.

\section{References}

1. Lo CM, Ngan H, Tso WK, et al: Randomized controlled trial of transarterial lipiodol chemoembolization for unresectable hepatocellular carcinoma. Hepatology 35: 1164-1171, 2002.

2. Llovet JM and Bruix J: Systematic review of randomized trials for unresectable hepatocellular carcinoma: chemoembolization improves survival. Hepatology 37: 429-442, 2003.

3. Poon RT, Fan ST, Lo CM, Liu CL and Wong J: Intrahepatic recurrence after curative resection of hepatocellular carcinoma: long-term results of treatment and prognostic factors. Ann Surg 229: 216-222, 1999.

4. Minagawa M, Makuuchi M, Takayama $T$ and Kokudo N: Selection criteria for repeat hepatectomy in patients with recurrent hepatocellular carcinoma. Ann Surg 238: 703-710, 2003.

5. Takada Y and Uemoto S: Liver transplantation for hepatocellular carcinoma: the Kyoto experience. J Hepatobiliary Pancreat Sci 17: 527-532, 2010.

6. Thomas MB, Jaffe D, Choti MM, et al: Hepatocellular carcinoma: consensus recommendations of the National Cancer Institute Clinical Trials Planning Meeting. J Clin Oncol 28: 3994-4005, 2010.

7. Llovet JM, Ricci S, Mazzaferro V, et al: Sorafenib in advanced hepatocellular carcinoma. N Engl J Med 359: 378-390, 2008.
8. Cheng AL, Kang YK, Chen Z, et al: Efficacy and safety of sorafenib in patients in the Asia-Pacific region with advanced hepatocellular carcinoma: a phase III randomised, doubleblind, placebo-controlled trial. Lancet Oncol 10: 25-34, 2009.

9. Wilhelm SM, Carter C, Tang L, et al: BAY 43-9006 exhibits broad spectrum oral antitumor activity and targets the $\mathrm{RAF} / \mathrm{MEK} / \mathrm{ERK}$ pathway and receptor tyrosine kinases involved in tumor progression and angiogenesis. Cancer Res 64: 7099-7109, 2004.

10. Chang YS, Adnane J, Trail PA, et al: Sorafenib (BAY 43-9006) inhibits tumor growth and vascularization and induces tumor apoptosis and hypoxia in RCC xenograft models. Cancer Chemother Pharmacol 59: 561-574, 2007.

11. Hoffmann K, Glimm H, Radeleff B, et al: Prospective, randomized, double-blind, multi-center, phase III clinical study on transarterial chemoembolization (TACE) combined with Sorafenib versus TACE plus placebo in patients with hepatocellular cancer before liver transplantation - HeiLivCa [ISRCTN24081794]. BMC Cancer 8: 349, 2008.

12. Abou-Alfa GK, Johnson P, Knox JJ, et al: Doxorubicin plus sorafenib vs doxorubicin alone in patients with advanced hepatocellular carcinoma: a randomized trial. JAMA 304: 2154-2160, 2010.

13. Hsu CH, Shen YC, Lin ZZ, et al: Phase II study of combining sorafenib with metronomic tegafur/uracil for advanced hepatocellular carcinoma. J Hepatol 53: 126-131, 2010.

14. Pawlik TM, Reyes DK, Cosgrove D, Kamel IR, Bhagat N and Geschwind JF: Phase II trial of sorafenib combined with concurrent transarterial chemoembolization with drugeluting beads for hepatocellular carcinoma. J Clin Oncol 29: 3960-3967, 2011.

15. Cabrera R, Pannu DS, Caridi J, et al: The combination of sorafenib with transarterial chemoembolisation for hepatocellular carcinoma. Aliment Pharmacol Ther 34: 205-213, 2011.

16. Petrini I, Lencioni M, Ricasoli M, et al: Phase II trial of sorafenib in combination with 5 -fluorouracil infusion in advanced hepatocellular carcinoma. Cancer Chemother Pharmacol 69: 773-780, 2012.

17. Yamanaka T, Shiraki K, Sugimoto K, et al: Chemotherapeutic agents augment TRAIL-induced apoptosis in human hepatocellular carcinoma cell lines. Hepatology 32: 482-490, 2000.

18. Shin EC, Seong YR, Kim CH, et al: Human hepatocellular carcinoma cells resist to TRAIL-induced apoptosis, and the resistance is abolished by cisplatin. Exp Mol Med 34: 114-122, 2002.

19. Ricci MS, Kim SH, Ogi K, et al: Reduction of TRAIL-induced Mcl-1 and cIAP2 by c-Myc or sorafenib sensitizes resistant human cancer cells to TRAIL-induced death. Cancer Cell 12: 66-80, 2007.

20. Koehler BC, Urbanik T, Vick B, et al: TRAIL-induced apoptosis of hepatocellular carcinoma cells is augmented by targeted therapies. World J Gastroenterol 15: 5924-5935, 2009.

21. Chen KF, Tai WT, Liu TH, et al: Sorafenib overcomes TRAIL resistance of hepatocellular carcinoma cells through the inhibition of STAT3. Clin Cancer Res 16: 5189-5199, 2010.

22. Ito T, Shiraki K, Sugimoto K, et al: Survivin promotes cell proliferation in human hepatocellular carcinoma. Hepatology 31: 1080-1085, 2000.

23. Okano H, Shiraki K, Inoue H, et al: Cellular FLICE/caspase8 -inhibitory protein as a principal regulator of cell death and survival in human hepatocellular carcinoma. Lab Invest 83: 1033-1043, 2003.

24. Shiraki K, Sugimoto K, Yamanaka Y, et al: Overexpression of X-linked inhibitor of apoptosis in human hepatocellular carcinoma. Int J Mol Med 12: 705-708, 2003.

25. Yamaguchi Y, Shiraki K, Fuke H, et al: Targeting of X-linked inhibitor of apoptosis protein or survivin by short interfering RNAs sensitize hepatoma cells to TNF-related apoptosisinducing ligand- and chemotherapeutic agent-induced cell death. Oncol Rep 14: 1311-1316, 2005.

26. Kim JW, Lee JO, Han SW, et al: Clinical outcomes of sorafenib treatment in patients with metastatic hepatocellular carcinoma who had been previously treated with fluoropyrimidine plus platinum-based chemotherapy. Am J Clin Oncol 34: 125-129, 2010.

27. Farazi PA and DePinho RA: Hepatocellular carcinoma pathogenesis: from genes to environment. Nat Rev Cancer 6: 674-687, 2006 . 
28. Llovet JM and Bruix J: Molecular targeted therapies in hepatocellular carcinoma. Hepatology 48: 1312-1327, 2008.

29. Koschny R, Walczak H and Ganten TM: The promise of TRAIL - potential and risks of a novel anticancer therapy. J Mol Med (Berl) 85: 923-935, 2007.

30. Johnstone RW, Frew AJ and Smyth MJ: The TRAIL apoptotic pathway in cancer onset, progression and therapy. Nat Rev Cancer 8: 782-798, 2008.

31. Huang S and Sinicrope FA: Sorafenib inhibits STAT3 activation to enhance TRAIL-mediated apoptosis in human pancreatic cancer cells. Mol Cancer Ther 9: 742-750, 2010.

32. Llobet D, Eritja N, Yeramian A, et al: The multikinase inhibitor Sorafenib induces apoptosis and sensitises endometrial cancer cells to TRAIL by different mechanisms. Eur J Cancer 46: 836-850, 2010

33. Heim M, Scharifi M, Zisowsky J, et al: The Raf kinase inhibitor BAY 43-9006 reduces cellular uptake of platinum compounds and cytotoxicity in human colorectal carcinoma cell lines. Anticancer Drugs 16: 129-136, 2005.
34. Willert $\mathrm{K}$ and Jones KA: Wnt signaling: is the party in the nucleus? Genes Dev 20: 1394-1404, 2006.

35. Kaidi A, Williams AC and Paraskeva C: Interaction between beta-catenin and HIF-1 promotes cellular adaptation to hypoxia. Nat Cell Biol 9: 210-217, 2007.

36. Lim JH, Chun YS and Park JW: Hypoxia-inducible factor1alpha obstructs a Wnt signaling pathway by inhibiting the hARD1-mediated activation of beta-catenin. Cancer Res 68: 5177-5184, 2008.

37. Mazumdar J, O'Brien WT, Johnson RS, et al: O2 regulates stem cells through Wnt/beta-catenin signalling. Nat Cell Biol 12: 1007-1013, 2010.

38. Lehwald N, Tao GZ, Jang KY, Sorkin M, Knoefel WT and Sylvester KG: Wnt-beta-catenin signaling protects against hepatic ischemia and reperfusion injury in mice. Gastroenterology 141: 707-718, 2011. 